\title{
An apparatus for partial ice-melting to improve yield
}

\section{in progressive freeze-concentration}

\author{
Mihiri Gunathilake, Michiko Dozen, Kiyomi Shimmura, Osato Miyawaki* \\ Department of Food Science, Ishikawa Prefectural University, 1-308 Suematsu, Nonoichi, Ishikawa 921-8836, Japan \\ *Corresponding author. Tel/Fax: +81 262277465 \\ E-mail address: osato@ishikawa-pu.ac.jp
}

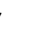

\begin{abstract}
A small test apparatus was made for partial melting of ice at controlled conditions in temperature and stirring speed. Ice cubes from $10 \mathrm{wt} \%$ sucrose were partially melted in this apparatus at 4 temperature and 4 stirring speeds. At the lower temperature with relatively faster stirring speed, the initially-melted fractions effectively contained the higher concentration of solute than the later-melted fractions. The partial ice-melting technique was combined with progressive freeze-concentration (PFC) to improve the yield in PFC. Apple juice
\end{abstract} with $13.7^{\circ}$ Brix was concentrated up to $25.5{ }^{\circ}$ Brix by PFC using a tubular ice system. Then, the partial ice-melting was applied for the ice formed by PFC to improve the yield from $63.8 \%$ to $85 \%$ by recovering the initial 30\% melted fraction. The partial ice-melting was also applied to pear (La France) juice flavor condensate. After 2.36 times concentration of flavor component (butyl acetate) by PFC, the yield was improved from 86.7\% to $95 \%$ by recovering the initial $35 \%$ melted fraction in the partial ice-melting process. Partial ice-melting technique will overcome the major drawback of PFC, in which the yield decreases with an increase in solute concentration because of the solute inclusion in the ice.

Key words: Progressive freeze-concentration, Partial ice-melting, Yield improvement, Solute inclusion in 


\section{Introduction}

Freeze-concentration has long being known as the best concentration method in terms of preserving original quality in the concentrated product (Deshpande et al., 1982). The low temperature operation in freeze-concentration prevents undesireble chemical, physical and biological changes that occur in other types of processing. Up to date, commercially available freeze-concentration method is known as suspension crystallization. This method requires a complicated system including surface-scraper heat-exchanger for seed ice, recrystallization vessel for ice crystal growth by Ostwald ripening mechanism, and washing tower to separate ice crystals from concentrated mother solution (Huige and Thijssen, 1972). Complexity of this system along with the high capital cost resulted in the limited practical use of this method for the concentration of liquid food.

Progressive freeze-concentration (PFC) is an alternative freeze concentration method where only a single ice crystal is formed on a cooling plate by a moving ice front (Matthews and Coggeshall, 1959; Shapiro, 1961; Miyawaki et al., 1998). Due to the ease of separation of concentrated solution, this method requires a simple system and a relatively cheap method than the suspension crystallization. A falling film reactor has developed for the scaling up of PFC (Flesland, 1995) and has applied for concentration of variety of liquid food (Hernandez et al., 2009, Hernandez et al., 2010, Sanchez et al., 2010, Sanchez et al., 2011). In this system, the ice crystal grows on a vertically placed cooling plate on which the solution to be concentrated flows as a falling film. Although this system is simple, the limited liquid flow rate on the cooling 
efficiency as expected by the concentration polarization theory (Miyawaki et al., 1998). In addition, this reactor has an open air surface which could lead to the loss of volatile flavor components. Retention of flavors is a major advantage in PFC (Ramos et al., 2005). Therefore, the PFC system should be designed in a way to minimize these losses. A closed tubular ice system with a circulating flow was developed for the scale-up of PFC, which provides a good mass transfer and a controlled heat transfer in a closed system (Miyawaki et al, 2005). This system is expected to give a high separation efficiency and a high-quality for the concentrated product especially in the retention of volatile flavors. osmotic pressure of sample because of the solute inclusion in the ice (Gu et al., 2005). To overcome this problem, we proposed partial ice-melting technique (Miyawaki et al., 2012), where the principle in the classical freezing-thawing technique was effectively applied.

In the freezing-thawing process, the initial melted fractions after freezing contains the higher concentration of solute than the later melted fractions. This phenomenon has been known from long time ago as the enrichment of ions from melting snow or ice in natural environment (Johannessen and Henriksen, 1978; Davies t al., 1982; Brimblecombe et al., 1987, 1988). This principle has been applied in desalination from sea water (Johnson, 1993; Khawaji et al., 2008; Mandri et al., 2011; Rich et al., 2012) and recently, various applications in industrial purpose have been explored (Yee et al., 2003, 2004; Nakagawa et al., 2009, 2010; Moreno et al., 2013, 2014). Only by freezing-thawing, however, concentration efficiency is limited so that multiple operations are inevitable (Aider and Halleux, 2008) to obtain a highly concentrated product, which requires a high energy consumption in the process. 
64 PFC will be an attractive option. In the previous paper, we successfully combined the partial ice-melting technique with PFC to improve the yield (Miyawaki et al., 2012). In this case, however, the experimental conditions in the thawing process were uncontrolled. In the present paper, we made a test apparatus for the melting of ice under the controlled conditions in temperature and stirring speed and applied it to improve the yield in PFC by the tubular ice system.

69

\section{Experimental method}

2.1 Materials

Sucrose and methyl butanoate were purchased from Kanto Kagaku (Tokyo, Japan). Apple juice was

supplied from Ishikawa Agriculture and Forestry Research Center. Pear (La France) juice flavor condensate is a by-product of vacuum evaporation of pear juice and was supplied by Kakoh Fruits and Flavors, Tokyo.

\subsection{Preparation of cube ice}

Ice cubes $(25 \times 25 \times 30 \mathrm{~mm})$ were prepared by freezing $10 \mathrm{wt} \%$ sucrose solution $(550 \mathrm{~mL})$ in an ice cube tray using a freezer (D-396DF3, Nihon Freezer, Japan) operated at $-35^{\circ} \mathrm{C}$.

\subsection{Progressive freeze-concentration}

A tubular ice system (Miyawaki et al., 2005) with circulating flow (MFC-10, Mayekawa, Tokyo) was used to concentrate apple juice and pear juice flavor condensate. This system consists of jacketed cylindrical tube (59.5 mm in diameter, $1800 \mathrm{~mm} \times 2$ in length), circulation pump, and feed tank. A coolant, the temperature of which was controlled by a controller and a refrigerator, was supplied to the jacket side of the tube to cool down 
the tube to form ice layer inside. Concentration process was controlled by the temperature program of the coolant and the speed of the circulation pump.

For apple juice, which was a solution with relatively high osmotic pressure, the seed ice lining step was necessary to improve the yield. For this purpose, the pure water was firstly introduced into the tubular system to form a small amount of seed ice on the cooling palate and the water was discharged. Then, precooled apple juice sample was introduced into the system to start PFC. After the concentration process, the concentrated solution was removed from the system and the coolant temperature was raised up to $20{ }^{\circ} \mathrm{C}$ to melt the ice surface formed in the system. Then, the ice slid out gravimetrically from the bottom of the tube. The ice taken out incorporated the small amount of the seed ice, the contribution of which was neglected in the analysis. The part of the ice was broken down into pieces and used for partial melting by the partial ice-melting vessel. not applied because of the low osmotic pressure of the sample which has a freezing point close to $0{ }^{\circ} \mathrm{C}$.

\subsection{Test apparatus for partial ice-melting}

A test apparatus (Fig. 1) was made for the partial melting of ice at a controlled temperature and a stirring speed. The apparatus is a jacketed vessel $(11 \mathrm{~cm}$ in diameter, $30 \mathrm{~cm}$ in depth) whose temperature was controlled by a circulation type cooler (TRL $108 \mathrm{H}$, Thomas, NJ, USA). The ice pieces were transferred into the vessel and stirred (SM-102, As one, Osaka) using a 4-blade, paddles blade stirrer (10 $\mathrm{cm}$ in diameter). The temperature was controlled at $0,2,10$, or $20^{\circ} \mathrm{C}$ and the stirring speed was at $0,50,100$, or $200 \mathrm{rpm}$. The melted ice fractions about 50-100 $\mathrm{ml}$ were collected at intervals and the volume and the solute concentration were measured. 

The concentrations in ${ }^{\circ}$ Brix were analyzed for original solution, concentrate after PFC, and partially melted ice fractions by a refractometer (APAL-1, As One, Osaka) for ice cube sample and apple juice. For pear juice flavor condensate, ${ }^{\circ}$ Brix was measured as a tentative index after concentration and partial ice-melting and flavor analysis by gas chromatography was carried out succeedingly. condensate sample. A $10 \mathrm{ml}$ sample, mixed with $40 \mathrm{ppm}$ methyl butanoate as an internal standard and $2.4 \mathrm{~g}$ of sodium chloride, was transferred into a $20 \mathrm{ml}$ screw-cap vial and heated up to $45^{\circ} \mathrm{C}$ for $5 \mathrm{~min}$ and then the SPME fiber (50/30um, DVB/CAR/PDMS (Grey), Supelco Analytical, PA, USA) was inserted into the head space of the vial for the extraction and adsorption of flavor components to the SPME fiber for $15 \mathrm{~min}$. Then, the SPME fiber was removed from the vial and was inserted into the injection port of gas chromatograph (GC) or gas chromatograph/mass spectroscopy (GC/MS) for releasing of flavors for $3 \mathrm{~min}$. kept at $250{ }^{\circ} \mathrm{C}$.

\section{Results and discussion}




\subsection{Partial melting of cube ice}

Figure $2 \mathrm{~A}$ shows the effect of thawing temperature on melting rate of cube ice of $10 \mathrm{wt} \%$ sucrose at a constant stirring rate of $100 \mathrm{rpm}$. As the freezing point of $10 \mathrm{wt} \%$ sucrose is $-0.625{ }^{\circ} \mathrm{C}$ (Weast, 1974), the actual driving force for the melting ice is the environmental temperature, controlled by the coolant, plus $0.625{ }^{\circ} \mathrm{C}$. The thawing rate was very slow at $0{ }^{\circ} \mathrm{C}$ and very fast at 10 or $20{ }^{\circ} \mathrm{C}$. In all the case, the thawing rate decreased with time because of the decrease in the driving force for ice-melting, which is affected by the freezing point of cube ice. The freezing point of the ice increases with time because of the selective elimination of solute during the thawing process. Figure 2B shows the effect of stirring speed on the melting rate of ice at a constant temperature of $2{ }^{\circ} \mathrm{C}$, which was chosen because of the too slow melting rate at $0{ }^{\circ} \mathrm{C}$. The melting rate of the ice increased with an increase in the stirring speed because of an increase in heat transfer to the ice phase from the jacket wall.

In Fig.3A, the effect of the thawing temperature is shown on the concentration change with time in the melted fractions. As was expected from the freezing-thawing principle, the initial fractions contain the higher solute concentration than the later fractions. This tendency was the most noticeable at $0{ }^{\circ} \mathrm{C}$ while the difference among the fractions diminished at $20{ }^{\circ} \mathrm{C}$. This suggests that the slow thawing at the temperature close to the freezing point of the sample is desirable to obtain the higher concentration gradient with time for melted fractions. At $0{ }^{\circ} \mathrm{C}$, the sucrose concentration of the first melted fraction was $19 \%$, which was almost two times that of the original solution. This corresponds to the possibility for freeze concentration only by the freezing-thawing technique although the separation efficiency is not so high so that the multiple operations are necessary in practice (Aider and Halleux, 2008). Figure 3B shows the effect of stirring on the concentration gradient with time for melted fractions at a fixed temperature of $2{ }^{\circ} \mathrm{C}$. The gradient increased with an increase in the stirring speed but its effect was not so apparent as in the effect of temperature. 
and stirring speed (thawing temperature at $2{ }^{\circ} \mathrm{C}$ ) on the change in yield during the partial melting process. At the

150 lower thawing temperature with the higher stirring speed, the discrepancy between the ice-melted fraction and the

151 yield increased. For example, the yield of $64 \%$ was obtained at the ice-melted fraction of $40 \%$ in the partial ice-melting process at the thawing temperature of $0{ }^{\circ} \mathrm{C}$ and the stirring speed of $100 \mathrm{rpm}$ (Fig.4A) showing the effectiveness of the partial ice-melting technique for the selective elution and enrichment of solute from the ice.

On the contrary, the yield at the thawing temperature of $20^{\circ} \mathrm{C}$ was almost the same with the fraction of melted ice.

This shows that too rapid thawing is not effective to obtain the concentration effect in partial ice-melting.

\subsubsection{Apple juice}

Although the partial ice-melting itself might be effective for the concentration of solute after freezing, this technique will be most effective if combined with PFC. Therefore, PFC of apple juice was carried out by the tubular ice system. As shown in Table 1, apple juice of $12.18 \mathrm{~L}$ was concentrated to $3.50 \mathrm{~L}$ (volumetric concentration ratio 3.48 ) and the concentration increased from 13.7 to 25.5 Brix. In this case, however, the ${ }^{\circ}$ Brix-based yield was $63.8 \%$ because of the solute inclusion in the ice, which contained solutes at $5.84{ }^{\circ} \mathrm{Brix}$ in average. formed in PFC of apple juice was broken into small pieces and was transferred into the partial ice-melting vessel operated at $0{ }^{\circ} \mathrm{C}$ with stirring speed at $100 \mathrm{rpm}$ in consideration of the results in the partial melting of $10 \mathrm{wt} \%$ sucrose ice. As shown in Fig.5, the concentrations of solute in the initially melted fractions were higher than those 
in the later fractions. By recovering the $30 \%$ of initial melted fractions, the yield improved from $63.8 \%$ up to

$17085 \%$ and this could be improved up to $90 \%$ if $50 \%$ initial fractions were recovered. This shows the 171 effectiveness of the partial ice-melting technique to improve the yield in PFC.

\subsubsection{Pear (La France) juice flavor condensate}

this contains various flavors as shown in Fig.6 and could be applicable as a high quality source of natural fruits flavors. This is a solution with much lower osmotic pressure than apple juice so that the higher yield is theoretically expected in PFC (Gu et al., 2005; Gunathilake et al., 2013). PFC of pear juice flavor condensate was carried out by the tubular ice system. As shown in Table 2, $12.18 \mathrm{~L}$ of original solution was freeze-concentrated to

3.32 L (volumetric concentration ratio 3.67). Although the ${ }^{\circ}$ Brix-based concentration was tentatively measured, ice by the relative concentration, based on the original solution of butylacetate (peak 3 in Fig.6). The yield obtained in this way was $86.7 \%$, which is much higher than the case with apple juice. For this sample, the partial yield improved up to $95 \%$ through the partial ice melting with the temperature at $0{ }^{\circ} \mathrm{C}$ and the stirring speed at $100 \mathrm{rpm}$.

The major advantage of the partial ice-melting combined with PFC, compared with the simple freezing-thawing technique, is that the concentrate at a certain level is firstly obtained in PFC step then the yield is improved in the partial ice-melting step. The recovered fraction is not necessarily mixed with the concentrate but rather recommended to be mixed with the original solution for the next concentration operation to avoid dilution 

is necessary and the concentration level is not so high so that a multi-step operation is necessary to obtain the higher concentration level.

\section{Conclusion}

Ice cubes from $10 \%$ sucrose were partially melted in a small test apparatus for partial melting of ice at

controlled conditions in temperature and stirring speed. At the lower temperature with relatively faster stirring speed, the initially-melted fractions contained the higher concentration of solute than the later-melted fractions.

This initial enrichment effect of solute in the partial ice-melting could be applicable to the concentration of solutes in a solution in accordance with the principle of classical freezing-thawing technique. The partial ice-melting technique was effectively combined with PFC to improve the yield in PFC, in which a major drawback was the lower yield because of the solute inclusion in the ice, especially for a highly concentrated sample. Apple juice with 13.7 Brix was concentrated up to 25.5 Brix by PFC using a tubular ice system. Then, the partial ice-melting was applied for the ice formed by PFC to improve the yield from $63.8 \%$ to $85 \%$ by recovering the initial $30 \%$ melted fraction. The partial ice-melting was also applied to pear (La France) juice flavor condensate. After 2.36 times concentration of flavor component (butyl acetate) by PFC, the yield was improved from $86.7 \%$ to $95 \%$ by recovering the initial 35\% melted fraction in the partial ice-melting process. The recovered fraction is not necessarily mixed with the concentrate but rather recommended to be mixed with the original solution for the next concentration operation to avoid dilution of the concentrate. 
Technical support by Ms. Chiaki Omote is highly appreciated. Apple juice was kindly gifted by Ishikawa

213 Agriculture and Forestry Research Center, and pear (La France) juice flavor condensate sample by Kakoh Fruits

214 and Flavors, Ltd. (Tokyo). This work was partly supported by A-Step program (AS2321218E) from Japan

215 Science and Technology Agency.

216

217

218 References

219 Aider, M., de Halleux, D., 2008. Passive and microwave-assisted thawing in maple sap cryoconcentration 220 technology. Journal of Food Engineering 85, 65-72.

221 Aider, M., de Halleux, D., 2008. Production of concentrated cherry and apricot juices by crycconcentration technology. LWT-Food Science and Technology 41, 1768-1775.

223

Aider, M., de Halleux, D., 2009. Cryoconcentration technology in the bio-food industry: Principles and applications. LWT-Food Science and Technology 42, 679-685.

Aider, M., Ounis W.B., 2012. Skim milk cryoconcentration as affected by the thawing mode: gravitational vs. microwave-assisted. International Journal of Food Science and Technology 47, 195-202.

Brimblecombe, P., Clegg, S.L., Davies, T.D., Shooter, M., Tranter, M., 1987. Observations of the preferential loss of major ions from melting snow and laboratory ice. Water Research 21, 1279-1286.

Brimblecombe, P., Clegg, S.L., Davies, T.D., Shooter, M., Tranter, M.,1988. The loss of halide and sulphate ions from melting ice. Water Research 22, 693-700.

Davies, T.D., Vincent, C.E., Brimblecombe, P., 1982. Preferential elution of strong acids from a Norwegian ice 
233 Deshpande, S.S., Bolin, H.R., Salunkhe, D.K., 1982. Freeze concentration of fruit juices. Food Technology 36, $234 \quad 68-82$.

235 Flesland. O., 1995. Freeze concentration by layer crystallization. Drying Technology 13, 1713-1739.

$236 \mathrm{Gu}, \mathrm{X}$., Suzuki, T., Miyawaki, O., 2005. Limiting partition coefficient in progressive freeze-concentration. $237 \quad$ Journal of .Food Science 70, 546-551.

238 Gunathilake, M., Shimmura, K., Miyawaki, O., 2013. Analysis of solute distribution in ice formed in progressive 239 freeze-concentration. Food Science and Technol. Research 19, 369-374.

240 Hernandez, E., Raventos, M., Auleda, J.M., Ibarz A., 2009. Concentration of apple and pear juices in a multi-plate 241 freeze concentrator. Innovative Food Science and Emerging Technologies 10, 348-355.

242 Hernandez, E., Raventos, M., Auleda, J.M., Ibarz A., 2010. Freeze concentration of must in a pilot plant falling 243 film cryoconcentrator. Innovative Food Science and Emerging Technologies 11, 130-136.

244 Huige, N.J.J., Thijssen, H.A.C., 1972. Production of large crystals by continuous ripening in a stirrer tank. Journal 245 of Crystal Growth 13/14, 483-487.

246 Johnson, W.E., 1993. The story of freeze desalting, Desalination and. Water Reuse 3, 20-27.

247 Johannsen, M., Henriksen, A., 1978. Chemistry of snow meltwater: Change in concentration during melting, 248 Water Resources Research 14, 615-619.

249 Khawaji, A.D., Kutubkhanah, I.K., Wie, J.M., 2008. Advances in seawater desalination technologies. 250 Desalination 221, 47-69.

251 Liu, L., Miyawaki, O., Nakamura, K., 1997. Progressive freeze-concentration of model liquid food, Food Science 252 and Technology International Tokyo 3, 348-352. 
254 2011. Parametric study of the sweating step in the seawater desalination process by indirect freezing.

255 Desalination 269, 142-147.

256 Matthews, J.S., Coggeshall, N.D., 1959. Concentration of impurities from organic compounds by progressive freezing. Analytical Chemistry 31, 1124-1125.

Miyawaki, O., Liu, L., Nakamura, K., 1998. Effective partition constant of solute between ice and liquid phases in progressive freeze-concentration. Journal of Food Science. 63, 756-758.

Miyawaki, O., Liu, L., Shirai, Y., Sakashita, S., Kagitani, K., 2005. Tubular ice system for scale-up of progressive freeze-concentration. Journal of Food Engineering 69, 107-113.

Miyawaki, O., Kato, S., Watabe, K., 2012. Yield improvement in progressive freeze-concentration by partial melting of ice. Journal of Food Engineering 108, 377-382.

Moreno, F.L., Robles, C.M., Sarmiento, Z., Ruiz, Y., Pardo, J.M., 2013. Effect of separation and thawing mode on block freeze-concentration of coffee brews. Food and Bioproducts Processing 91, 396-402. $158-166$.

Nakagawa, K., Maebashi, S., Maeda, K., 2009. Concentration of aqueous dye solution by freezing and thawing. The Canadian Journal of Chemical Engineering 87, 779-787.

Nakagawa, K., Maebashi, S., Maeda, K., 2010a. Freeze-thawing as a path to concentrate aqueous solution. Separation and Purification Technology 73, 403-408. 
Ramos, F.A., Delgado, J.L., Bautista, E., Morales, A.L., Duque, C., 2005. Change in volatiles with the application of progressive freeze-concentration to Andes berry (Rubus glaucus Benth). Journal of Food Engineering 69, 291-297.

Rich, A., Mandri, Y., Mangin, D., Rivoire, A., Abderafi, S., Bebon, C., Semlali, N., Klein, J.P., Bounahmidi, T., Bouhaouss, A., Veesler, S., 2012 Sea water desalination by dynamic layer melt crystallization: Parametric study of the freezing and sweating steps. Journal of Crystal Growth 342, 110-116.

Sanchez, J., Ruiz, Y., Raventos, M., Auleda, J.M., Hernandez, E., 2010. Progressive freeze concentration of orange juice in a pilot plant falling film. Innovative Food Science and Emerging Technologies 11, 644-651.

Sanchez, J., Hernandez, E., Auleda, J.M., Raventos, M., 2011. Freeze concentration of whey in a falling-film based pilot plant: Process and characterization. Journal of Food Engineering 103, 147-155.

Shapiro, J., 1961. Freezing-out, a safe technique for concentration of dilute solutions. Science 133, 2063-2064.

Watanabe, A., Miyawaki, O., Watanabe, M., Suzuki, T., 2013. Mechanism of solute incorporation into ice phase in progressive freeze-concentration. Japan Journal of Food Engineering, 14, 163-168.

Weast, R.C. 1974. Handbook of Chemistry and Physics. (56 ${ }^{\text {th }}$ ed.; D-261). Cleveland: CRC Press. 
$\underline{\text { Table } 1 \text { Progressive freeze-concentration of apple juice by tubular ice system }}$

297

298

299

300

301

302

303

304

305

306

307

308

309

310

311

312

313

314

315

316

317

\begin{tabular}{|c|c|c|c|}
\hline & Volume(L) & $\begin{array}{l}\text { Concentration } \\
\left({ }^{\circ} \text { Brix }\right)\end{array}$ & Yield \\
\hline Original solution & 12.18 & 13.7 & - \\
\hline Concentrate & 3.50 & 25.5 & 0.638 \\
\hline Ice & 8.68 & 5.84 & 0.362 \\
\hline Conc. ratio & 3.48 & 1.86 & \\
\hline
\end{tabular}

$\underline{\text { Table } 2 \text { Progressive freeze-concentration of pear juice flavor condensate by tubular ice system }}$

\begin{tabular}{lcccc}
\hline & Volume(L) & $\begin{array}{c}\text { Concentration } \\
\left({ }^{\circ} \text { Brix }\right)\end{array}$ & $\begin{array}{c}\text { Relative conc. } \\
\text { of butylacetate }\end{array}$ & Yield \\
\hline Original solution & 12.18 & 1.0 & 1.0 & - \\
Concentrate & 3.32 & 2.7 & $2.36^{*}$ & 0.867 \\
Ice & 8.86 & 0.7 & $0.135^{*}$ & 0.133 \\
Conc. ratio & 3.67 & 2.7 & 2.36 & \\
\hline
\end{tabular}

*) Relative value compared to original solution. 
319 Fig. 1 A test apparatus for partial ice-melting.

320 Fig. 2 Effects of melting-temperature (A: stirring speed, 100rpm) and stirring speed (B: melting temperature, 2 $\left.{ }^{\circ} \mathrm{C}\right)$ on melting volume of cube ice from $10 \mathrm{wt} \%$ sucrose.

322 Fig. 3 Effects of melting-temperature (A: stirring speed, 100rpm) and stirring speed (B: melting temperature, 2 $\left.{ }^{\circ} \mathrm{C}\right)$.on concentration distribution among partially melted fractions of cube ice from $10 \%$ sucrose

Fig. 4 Dependence of yield-improvement effect on melting-temperature (A: stirring speed, 100rpm).and stirring speed (B: melting temperature, $2{ }^{\circ} \mathrm{C}$ ) in partial melting of cube ice from $10 \%$ sucrose.

Fig. 5 Yield improvement based on ${ }^{\circ}$ Brix by partial melting of ice formed in progressive freeze-concentration of apple juice (melting temperature, $0^{\circ} \mathrm{C}$; stirring speed, 100rpm).

Fig. 6 Head space SPME chromatogram for pear (La France) juice flavor condensate.

Fig. 7 Yield improvement based on butylacetate by partial melting of ice formed in progressive 
Fig.1

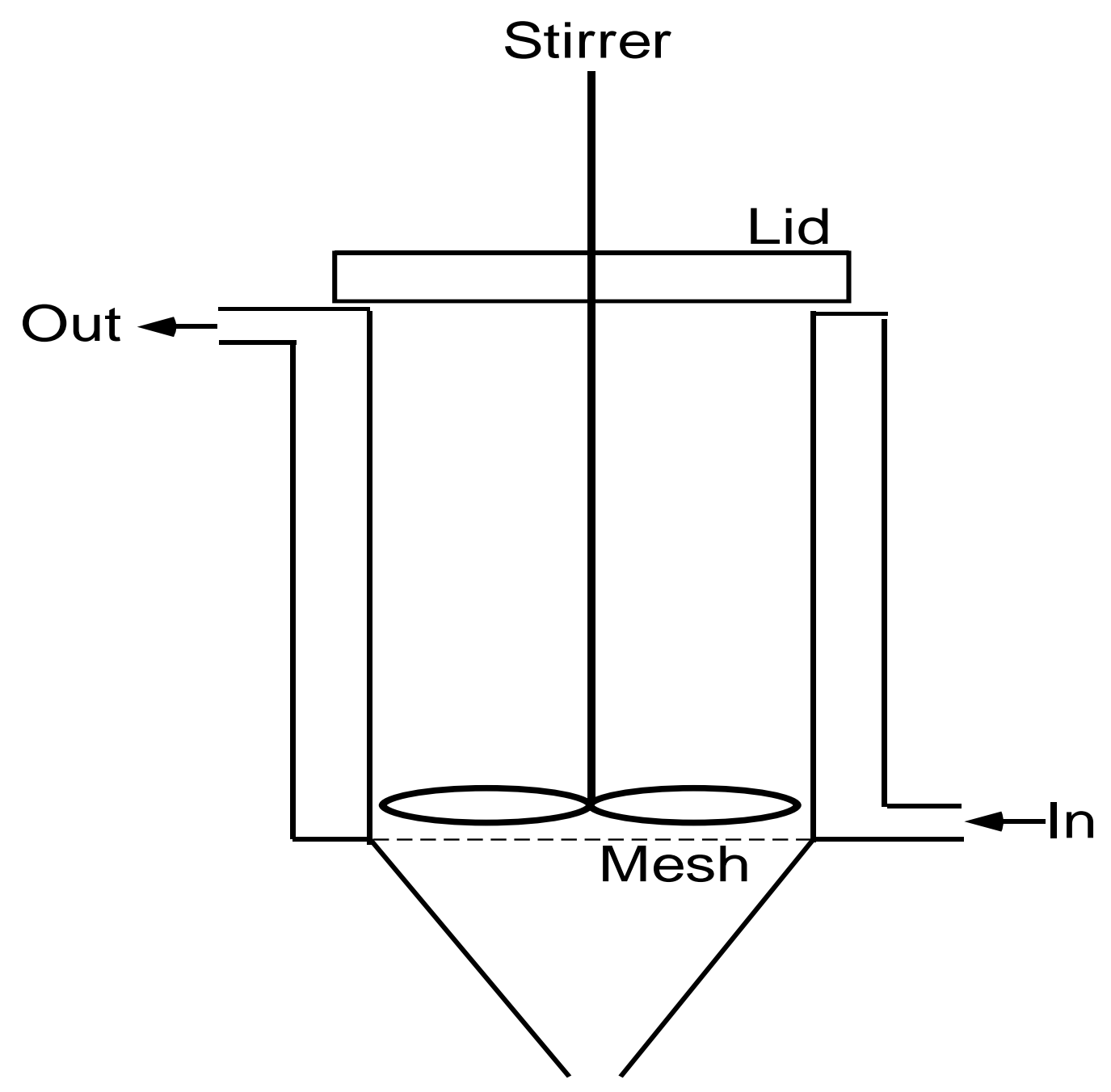


Fig.2A

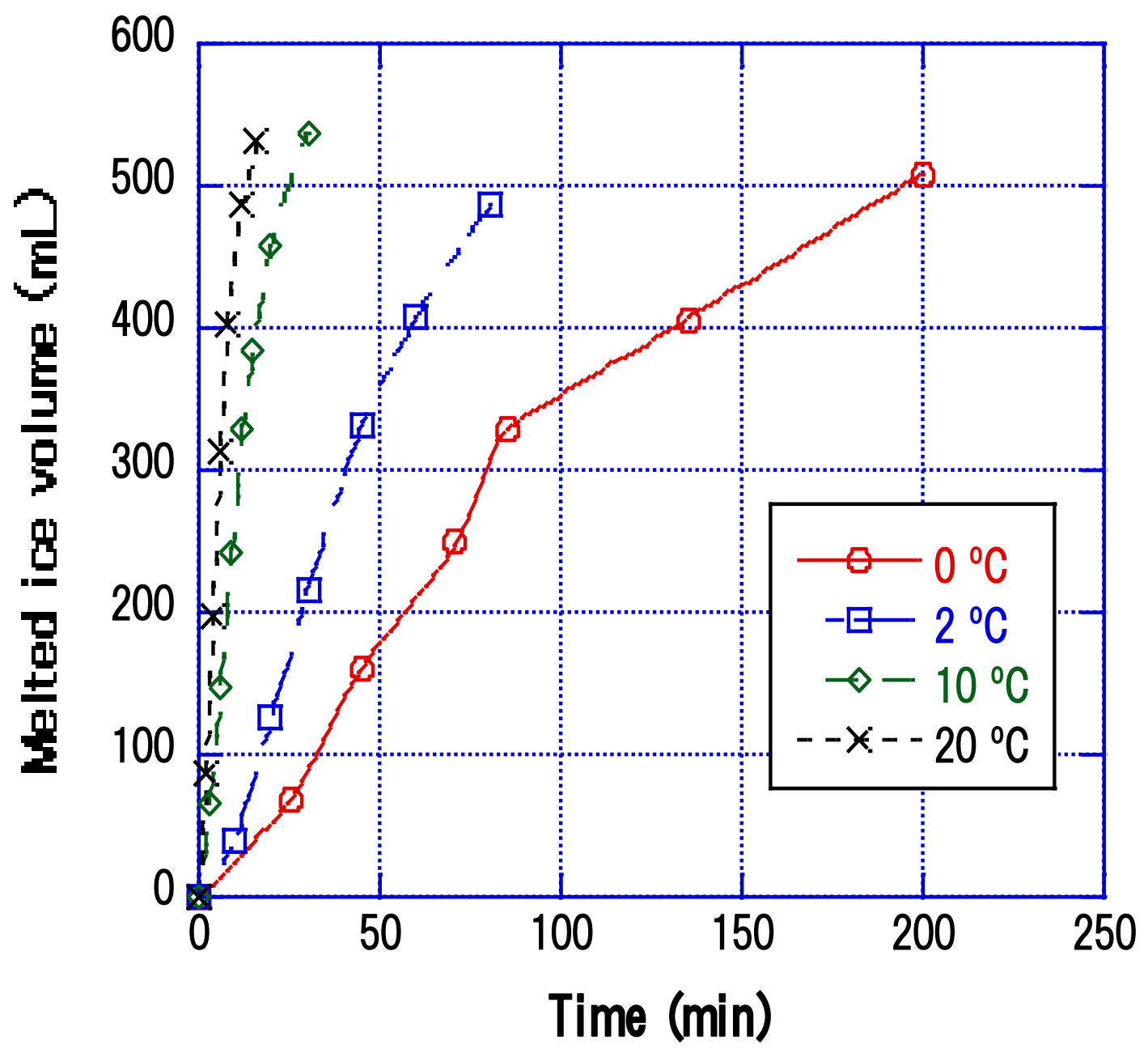




\section{Fig.2B}

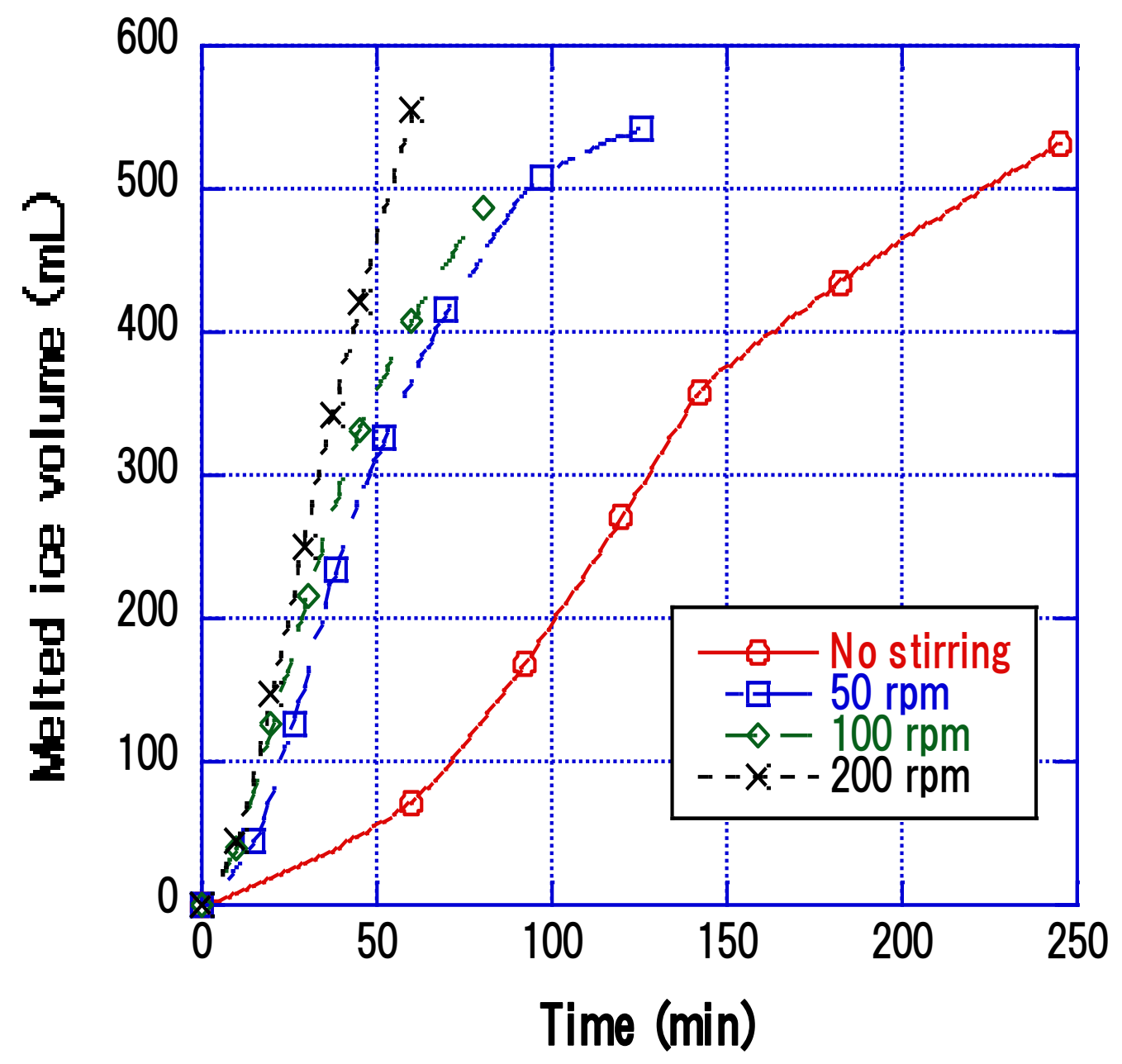




\section{Fig.3A}

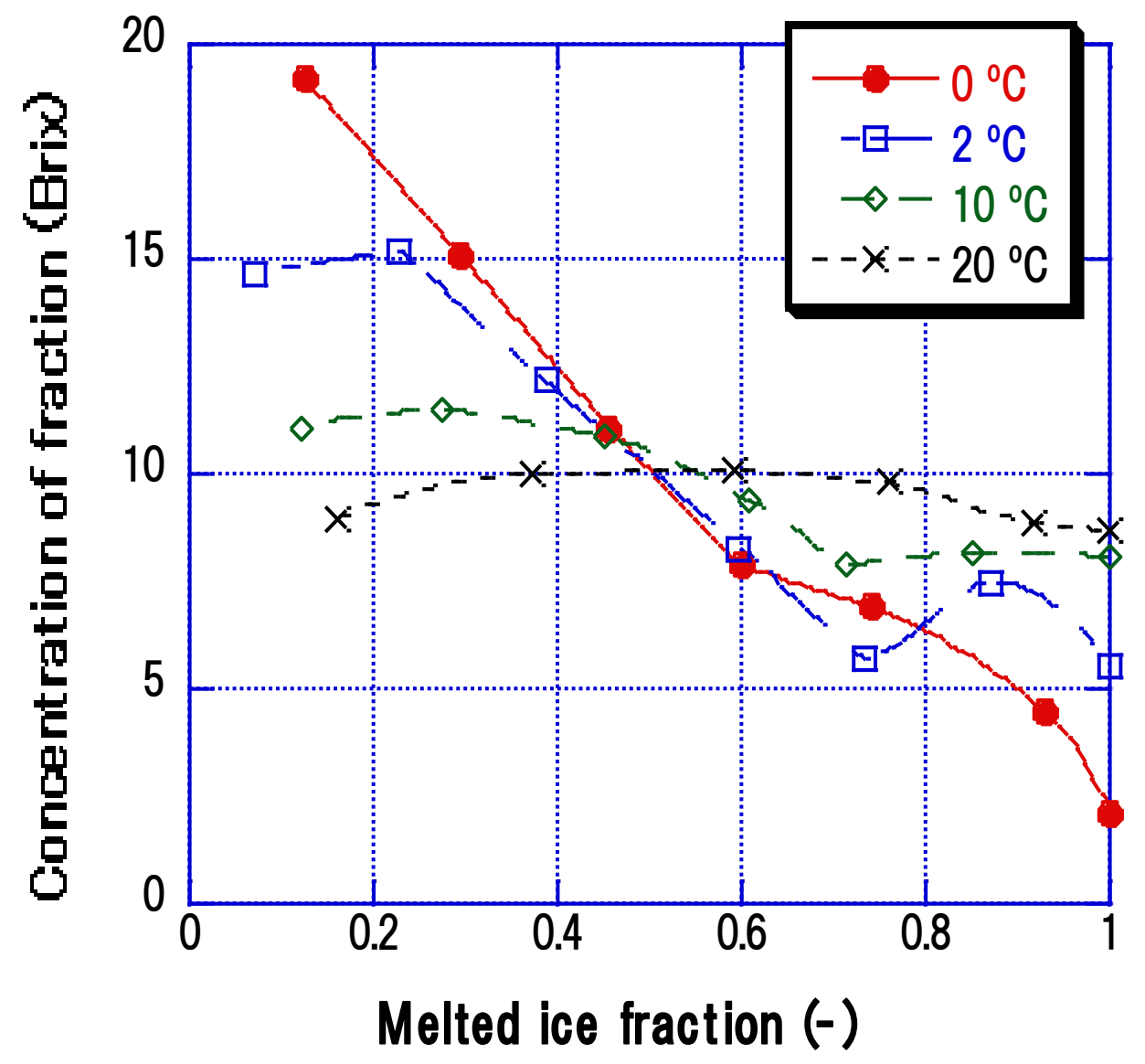


Fig.3B

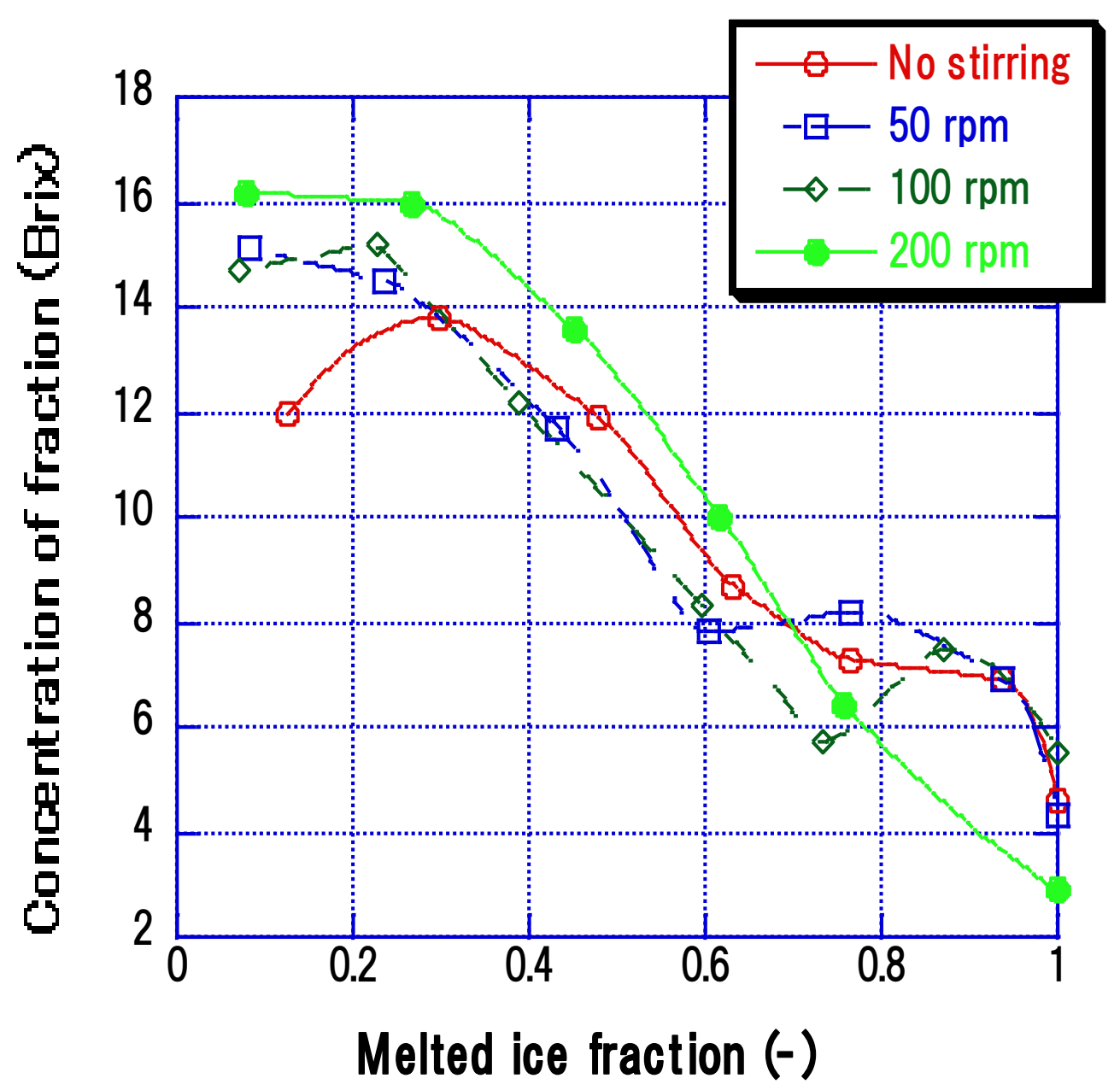




\section{Fig.4A}

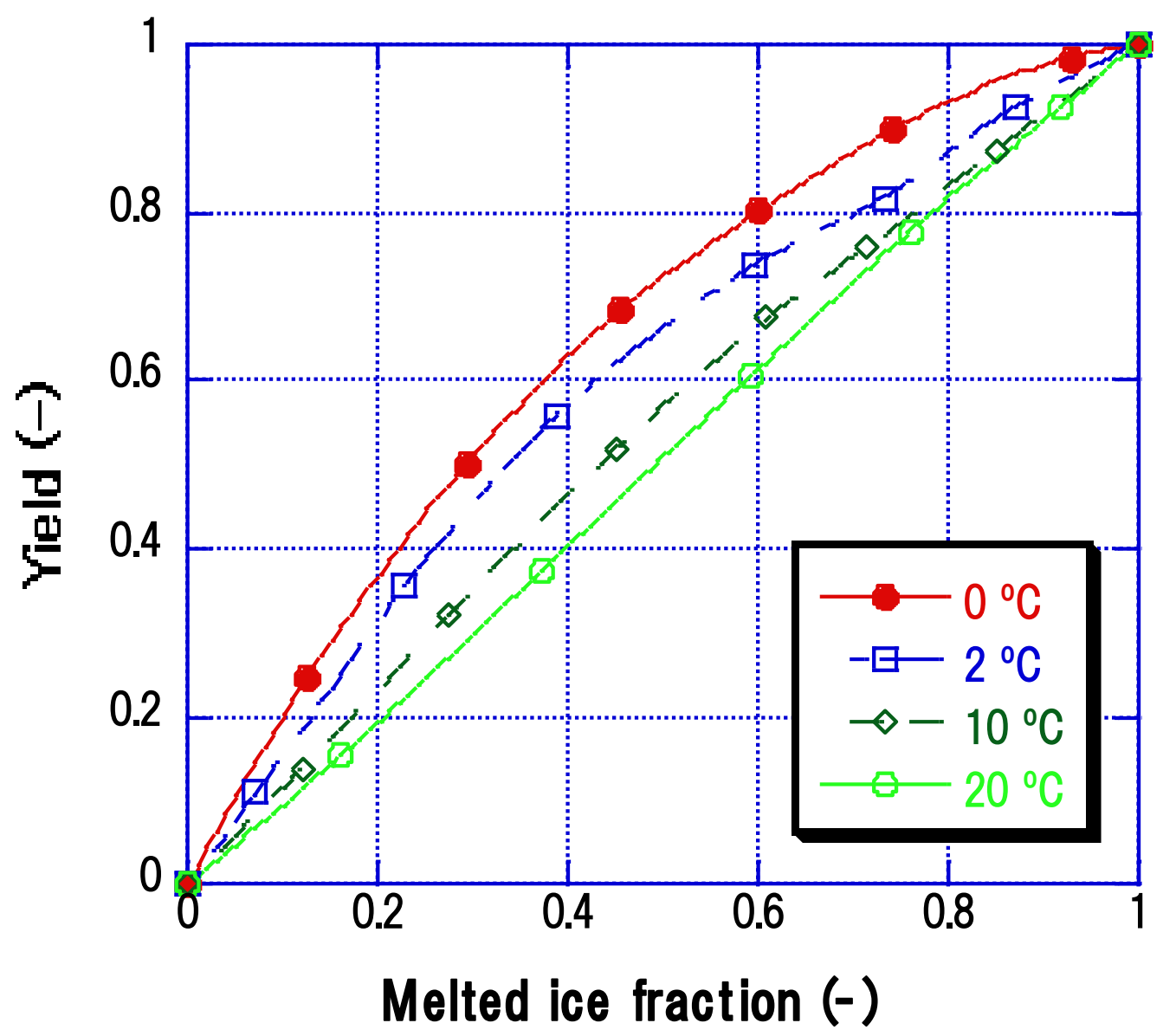




\section{Fig.4B}

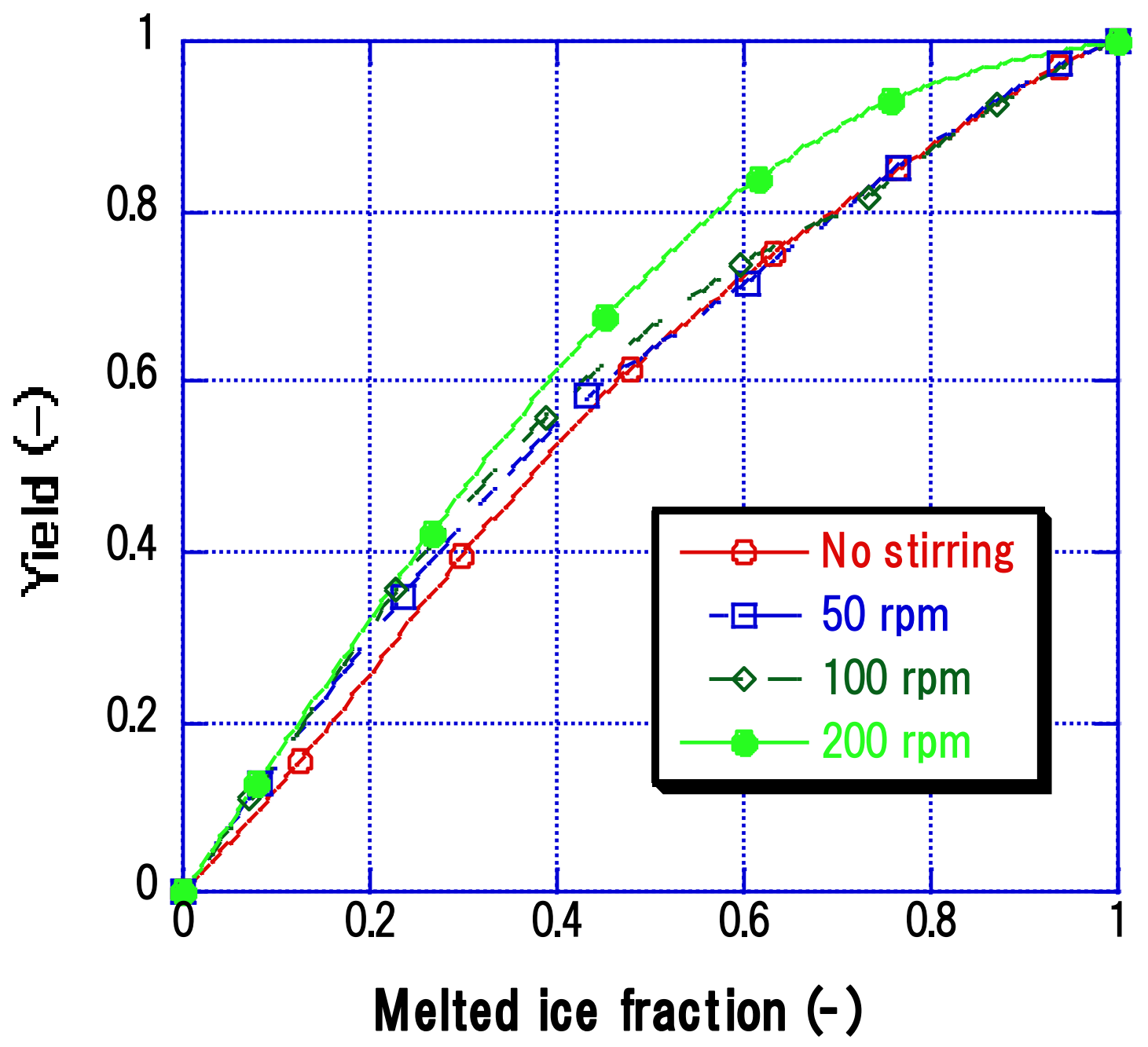


Fig.5

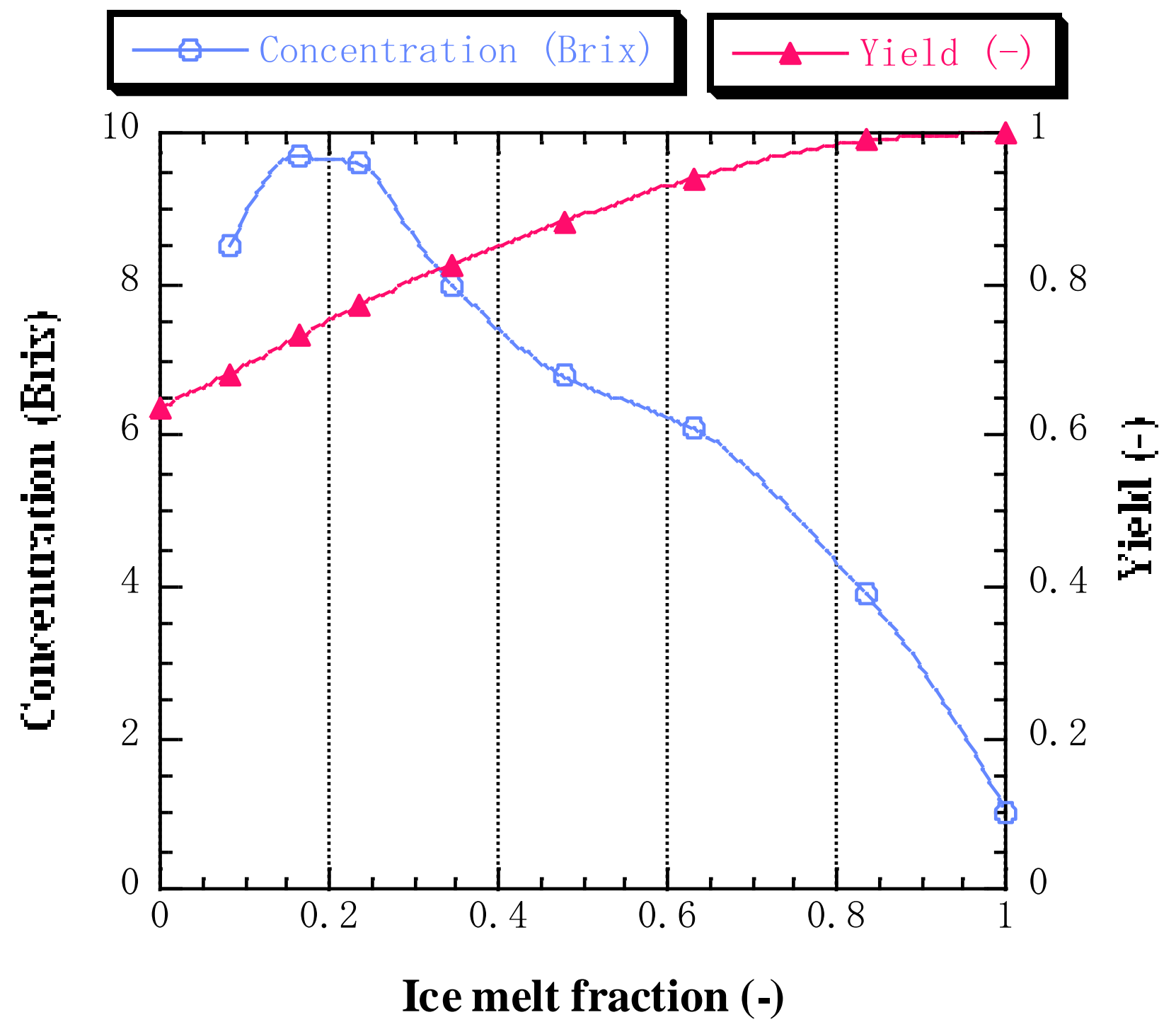




\section{Fig.6}

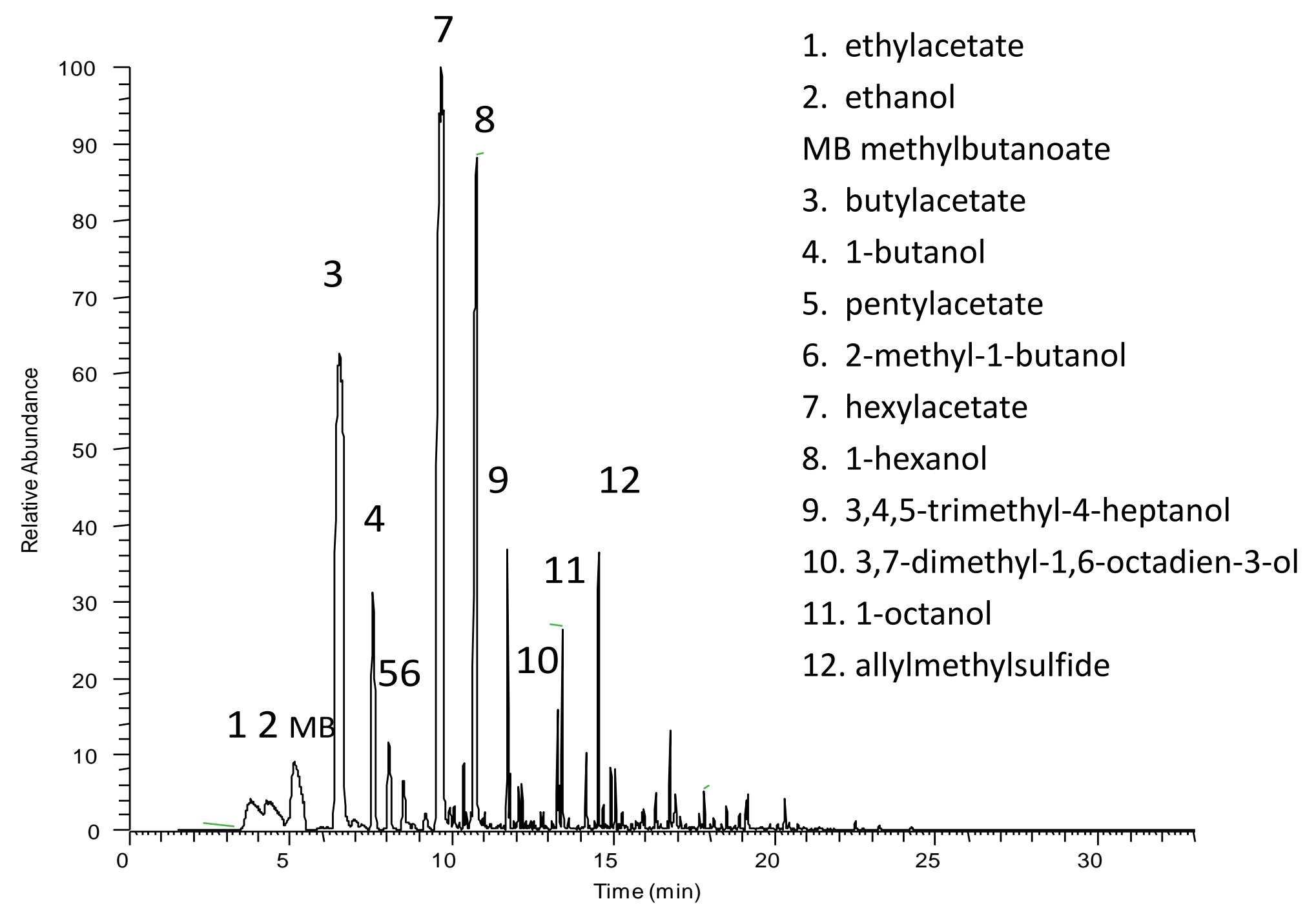


Fig.7

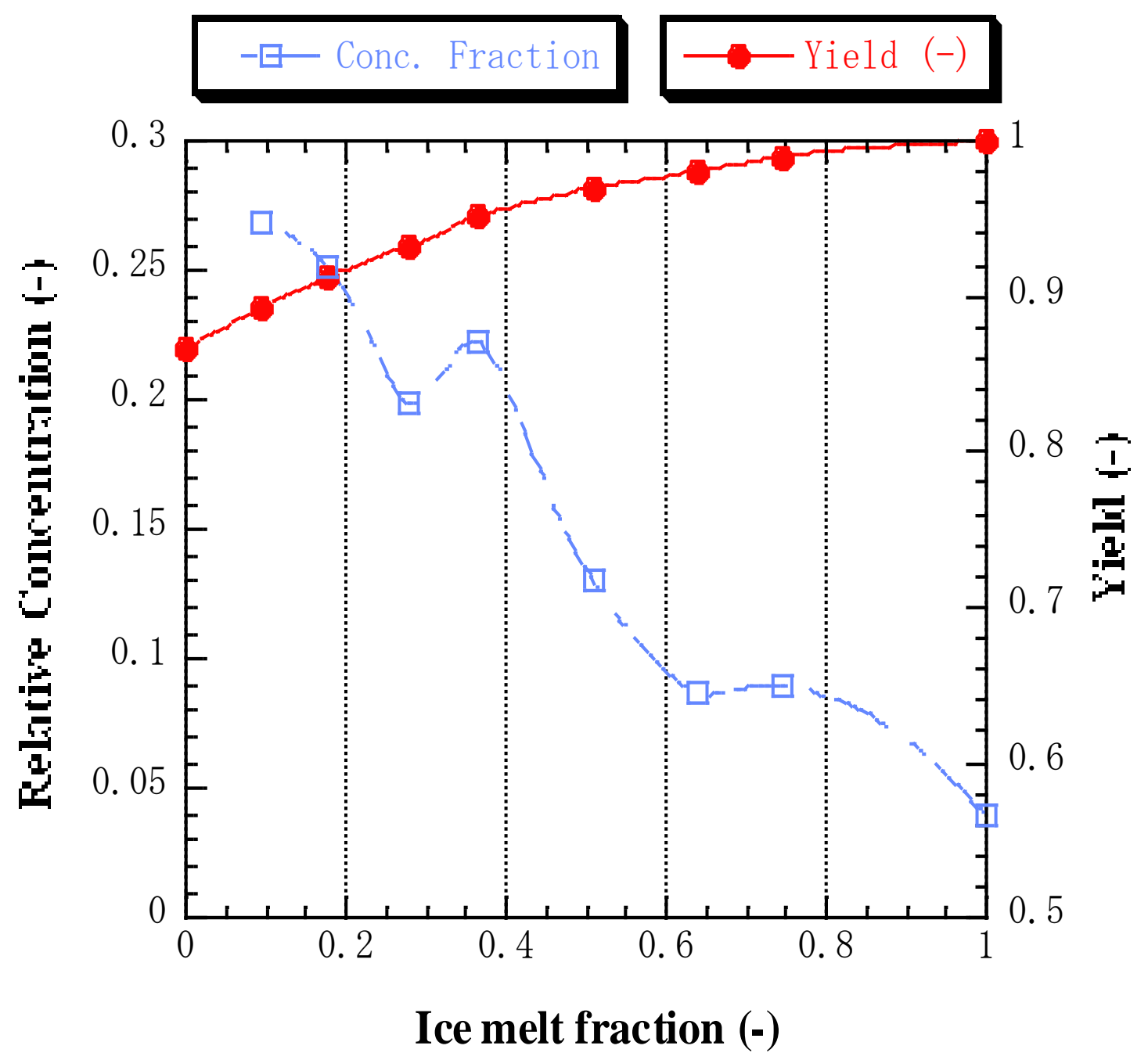

